\title{
Meta-Herpetic Keratitis and Therapeutic Approach: Case Report
}

\author{
Ozlem Sahin \\ Department of Ophthalmology/Uveitis, DunyaGoz Hospital Ltd., Ankara, Turkey \\ Email: ozlem1158@yahoo.com \\ Received 27 May 2014; revised 30 June 2014; accepted 23 July 2014 \\ Copyright (C) 2014 by author and Scientific Research Publishing Inc. \\ This work is licensed under the Creative Commons Attribution International License (CC BY). \\ http://creativecommons.org/licenses/by/4.0/

c) (†) Open Access

\begin{abstract}
The purpose of this study is to disclose the steps in the therapeutic approach for meta-herpetic corneal ulcer. Report of a case with anterior segment photography was used. The 6 months of follow-up results of the case were disclosed. The efficacy of the therapeutic approach for meta-herpetic corneal ulcer was discussed.
\end{abstract}

\section{Keywords}

\section{Corneal Ulcer, Corneal Neovascularization, Herpes Simplex Virus-1, Meta-Herpetic Keratitis}

\section{Introduction}

Herpes simplex virus type 1 (HSV-1) is regarded as a common cause of keratitis [1]. The clinical types of keratitis caused by HSV-1 is classified as epithelial keratitis, (dendritica, geographica) stromal keratitis, (necrotizing, non-necrotizing) endotheliitis, (disciform keratitis) meta-herpetic keratitis, (neurotrophic keratopathy) and vascularized corneal scars [1]. Meta-herpetic corneal disease is considered as a chronic or chronic recurrent superficial post-herpetic corneal inflammation without any detectable HSV-1-activity [2]. Meta-herpetic erosion, ulcer and bullous keratopathy are the main types of meta-herpetic corneal disease [2]. Metaherpetic corneal inflammation is widely considered a therapeutic challenge. The purpose of this study is to disclose the steps in the therapeutic approach for meta-herpetic corneal ulcer.

\section{Case Report}

75-year-old male admitted with the symptoms of redness, tearing, photophobia and blurred vision in the right eye. He had a history of right recurrent HSV-1 epithelial keratitis in the last 2 years. He had been treated with only topical antiviral medications. The last episode of HSV-1 epithelial keratitis was 6 months ago. Best corrected visual acuities (BCVA) on admission were 20/400 in the right eye and 20/20 in the left eye. The intra- 
ocular pressures were 10 and $8 \mathrm{~mm} \mathrm{Hg}$ respectively. Biomicroscopic examination of the right eye disclosed a centrally locateddeep corneal ulcer with smooth edges associated with stromal inflammation, descemet's folds and 270 degrees of peripheral corneal neovascularization 1 - $5 \mathrm{~mm}$ from the limbus (Figure 1). He had a posterior chamber intraocular lens. (PCIOL) Biomicroscopic examination of the left eye disclosed a PCIOL and fundus examination of both eyes were normal. The corneal scraping specimens for bacterial and fungal cultures were negative. He was diagnosed as meta-herpetic corneal ulcer in theright eye. Treatment with valacyclovir $1000 \mathrm{mg}$ twice a day, fibronectin drops prepared from the patient's serum, sustained release doxycycline, vitamin C, loteprednol etabonate (LE) associated with frequent use of preservative free artificial tears were initiated. Biomicroscopic examination at the $3^{\text {rd }}$ week of follow-up revealed the healing of corneal ulcer, decrease stromal inflammation with the resolution of descemet's folds and diminished peripheral corneal neovascularization (Figure 2). He received the same treatment with decreasing doses of LE for 6 months. His examination at the $6^{\text {th }}$ month of treatment revealed an increase in BCVA of the right eye to 20/40. Right cornea disclosed a central deep stromal scar without inflammation and neovascularization associated with sub-epithelial irregularities (Figure 3).

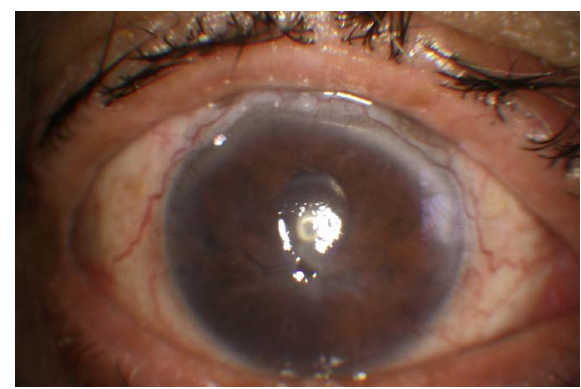

Figure 1. Anterior segment photo of the right cornea. Note centrally located deep corneal ulcer with smooth edges associated with stromal inflammation, descemet's folds and peripheral corneal neovascularization.

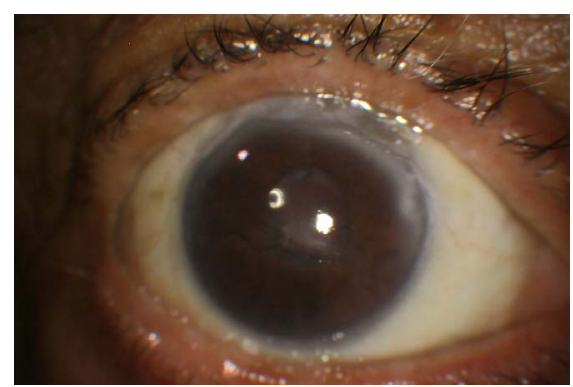

Figure 2. Anterior segment photo of the right cornea in the $3^{\text {rd }}$ week of follow-up. Note healing of the corneal ulcer, decreased stromal inflammation with the resolution of descemet's folds and diminished peripheral corneal neovascularization.

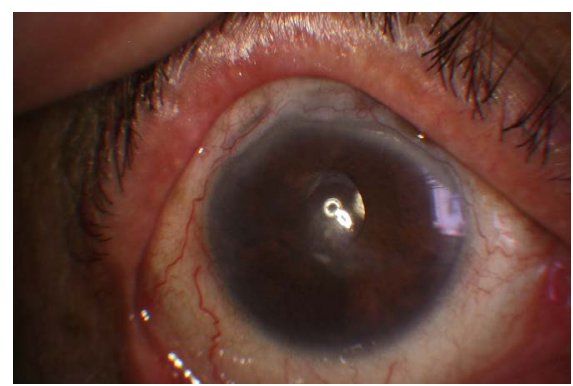

Figure 3. Anterior segment photo of the right cornea at the $6^{\text {th }}$ month of follow-up. Note a central deep stromal scar without inflammation and corneal neovascularization associated with sub-epithelial irregularities. 


\section{Discussion}

Meta-herpetic keratitis is described as a structural damage by the immune and inflammatory mechanisms in the aftermath of HSV-1 corneal infection [3]. The rupture of the Bowman's membrane with collagenases is shown to make the deep corneal ulcer possible [4]. Diagnosis of meta-herpetic keratitis is primarily based on a prior history of HSV-1 keratitis [5]. Serological investigations are not usually necessary [5]. This case had a history of recurrent epithelial keratitis treated with only topical antiviral medications. However, oral acyclovir has been recommended for the treatment of recalcitrant epithelial, stromal or uveal diseases secondary to HSV-1 [6]. The patient received inadequate treatment for recurrent HSV-1 keratitis. Diagnosis of meta-herpetic keratitis in this case was made on the basis of his prior history, biomicroscopic findings of deep ulcer with smooth edges associated with stromal inflammation, peripheral corneal neovascularization, and no growth of bacteria or fungi from the corneal scraping specimens. Treatment of meta-herpetic keratitis is challenging. Topical steroids are generally contraindicated in the presence of HSV epithelial keratitis [5] [6]. However, judicious topical steroid therapy is considered beneficial when combined with protective anti-viral coverage [5] [6]. The patient was treated with LE $0.5 \%$ five times a day. LE was shown to be highly lipophilic, and the highest concentrations of LE were reported to be found in the cornea followed by the iris, ciliary body and the aqueous humor [7]. Previous studies related to comparison of oral anti-viral therapy with valacyclovir or acyclovir revealed similar anti-viral potencies with less frequent dosages of valacyclovir [8] [9]. Valacyclovir 500 - 1000 mg twice a day is found as effective as acyclovir $200 \mathrm{mg}$ five times a Day [9]. Valacyclovir has been recommended for the patients having difficulty in complying with the acyclovir doses [10]. The patient received valacyclovir $1000 \mathrm{mg}$ twice a day with clinical improvement in 6 months. The efficacy of fibronectin eye drops which are prepared from patients own blood plasma has been shown for the non-healing corneal epithelial defects after HSV-1 keratitis [11]. This case was treated with fibronectin eye drops for the deep seated central corneal ulcer. The expression of matrix metalloproteinase (MMPs) by resident corneal cells or by inflammatory cells has been disclosed in experimental HSV-1 keratitis [12]. MMPs have been considered to promote epithelial keratitis, ulcerative process and stromal liquefaction after corneal HSV-1 infection [12]. Combining antiviral therapy with MMPs inhibitors has been revealed to speed corneal healing [13]. MMPs inhibitors are considered to inhibit corneal neovascularization by inhibiting the expression of vascular endothelial growth factor and the interleukin-1 $\beta$ [14] [15]. This case received sustained release doxycycline for 6 months. The deep central corneal ulcer and peripheral corneal neovascularization were resolved with this treatment at the end of $6^{\text {th }}$ month. Topical or systemic administrations of vitamin $\mathrm{C}$ or ascorbic acid have been shown to reduce corneal stromal inflammation through inhibition of polymorphonuclear leukocytes by the previous studies [16] [17]. The patient was treated with vitamin C orally for 6 months to promote the healing of the corneal ulcer. In conclusion; meta-herpetic keratitis is difficult to treat. We recommend early onset of systemic antiviral therapy in conjunction with smart use of topical steroids, MMPs inhibitors, vitamin C, fibronectin eye drops and preservative free lubricants.

\section{Funding}

Author does not have grants or funds in support of the study.

\section{References}

[1] Seitz, B. and Heiligenhaus, A. (2011) Herpetic Keratitis. Various Expressions Require Different Therapeutic Approaches. Ophthalmologe, 108, 385-395. http://dx.doi.org/10.1007/s00347-011-2346-5

[2] Sundmacher, R. and Neumann-Haefelin, D. (1976) Meta-Herpetic Keratitis Clinical and Virological Findings. Klin Monbl Augenheilkd, 169, 728-737.

[3] Liesegang, T.J. (1999) Classification of Herpes Simplex Virus Keratitis and Anterior Uveitis. Cornea, 18, $127-143$. http://dx.doi.org/10.1097/00003226-199903000-00001

[4] Algan, B. (1978) Considerations on the Meta-Herpetic Keratitis. Klin Monbl Augenheilkd, 172, 609-616.

[5] Wilhelmus, K.R. (1987) Diagnosis and Management of Herpes Simplex Stromal Keratitis. Cornea, 6, 286-291. http://dx.doi.org/10.1097/00003226-198706040-00011

[6] Schwab, I.R. (1988) Oral Acyclovir in the Management of Herpes Simplex Ocular Infections. Ophthalmology, 95, 423430. http://dx.doi.org/10.1016/S0161-6420(88)33156-8

[7] Comstock, T.L. and Decory, H.H. (2012) Advances in Corticosteroid Therapy for Ocular Inflammation: Loteprednol 
Etabonate. International Journal of Inflammation, 2012, Article ID: 789623.

[8] Goldblum, D., Bachmann, C., Tappeiner, C., et al. (2008) Comparison of Oral Antiviral Therapy with Valacyclovir or Acyclovir after Penetrating Keratoplasty for Herpetic Keratitis. British Journal of Ophthalmology, 92, 1201-1205. http://dx.doi.org/10.1136/bjo.2008.138065

[9] Perry, C.M. and Faulds, D. (1996) Valacyclovir: A Review of Its Antiviral Activity, Pharmacokinetic Properties and Therapeutic Efficacy in Herpes Virus Infections. Drugs, 52, 754-772. http://dx.doi.org/10.2165/00003495-199652050-00009

[10] Shimomura, Y. (2008) 1 Herpes Simplex Virus Latency, Reactivation and a New Antiviral Therapy for Herpetic Keratitis. Nihon Ganka Gakkai Zasshi, 12, 247-264.

[11] Nishida, T., Nakagawa, S. and Manabe, R. (1985) Clinical Evaluation of Fibronectin Eye Drops on Epithelial Disorders after Herpetic Keratitis. Ophthalmology, 92, 213-216. http://dx.doi.org/10.1016/S0161-6420(85)34050-2

[12] Yang, Y.N., Bauer, D., Li, H.P., et al. (2004) Expression of Matrix Metalloproteinases in Experimental Herpes Simplex Virus Keratitis. Zhonghua Yan Ke Za Zhi, 40, 395-399.

[13] Brooks, D.E. and Ollivier, F.J. (2004) Matrix Metalloproteinase Inhibition in Corneal Ulceration. Veterinary Clinics of North America: Small Animal Practice, 34, 611-622. http://dx.doi.org/10.1016/j.cvsm.2003.12.005

[14] Peyman, G.A., Kazi, A.A., Riazi-Estafani, M., et al. (2006) The Effect of Combinations of Flurbiprofen, Low Molecular Weight Heparin and Doxycycline on the Inhibition of Corneal Neovascularization. Cornea, 25, 582-585. http://dx.doi.org/10.1097/01.ico.0000220767.73660.3a

[15] Ling, S., Li, W., Liu, L., et al. (2013) Allograft Survival Enhancement Using Doxycycline in Alkali-Burned Mouse Cornea. Acta Ophthalmologica, 91, 369-378.

[16] Gunby, P. (1980) Vitamin C May Enhance Healing of Caustic Corneal Burns. JAMA, 243, 623. http://dx.doi.org/10.1001/jama.1980.03300330003001

[17] Pfister, R.P. and Paterson, C.A. (1980) Ascorbic Acid in the Treatment of Alkali Burns of the Eye. Ophthalmology, 87, 1050-1057. http://dx.doi.org/10.1016/S0161-6420(80)35126-9 
Scientific Research Publishing (SCIRP) is one of the largest Open Access journal publishers. It is currently publishing more than 200 open access, online, peer-reviewed journals covering a wide range of academic disciplines. SCIRP serves the worldwide academic communities and contributes to the progress and application of science with its publication.

Other selected journals from SCIRP are listed as below. Submit your manuscript to us via either submit@scirp.org or Online Submission Portal.
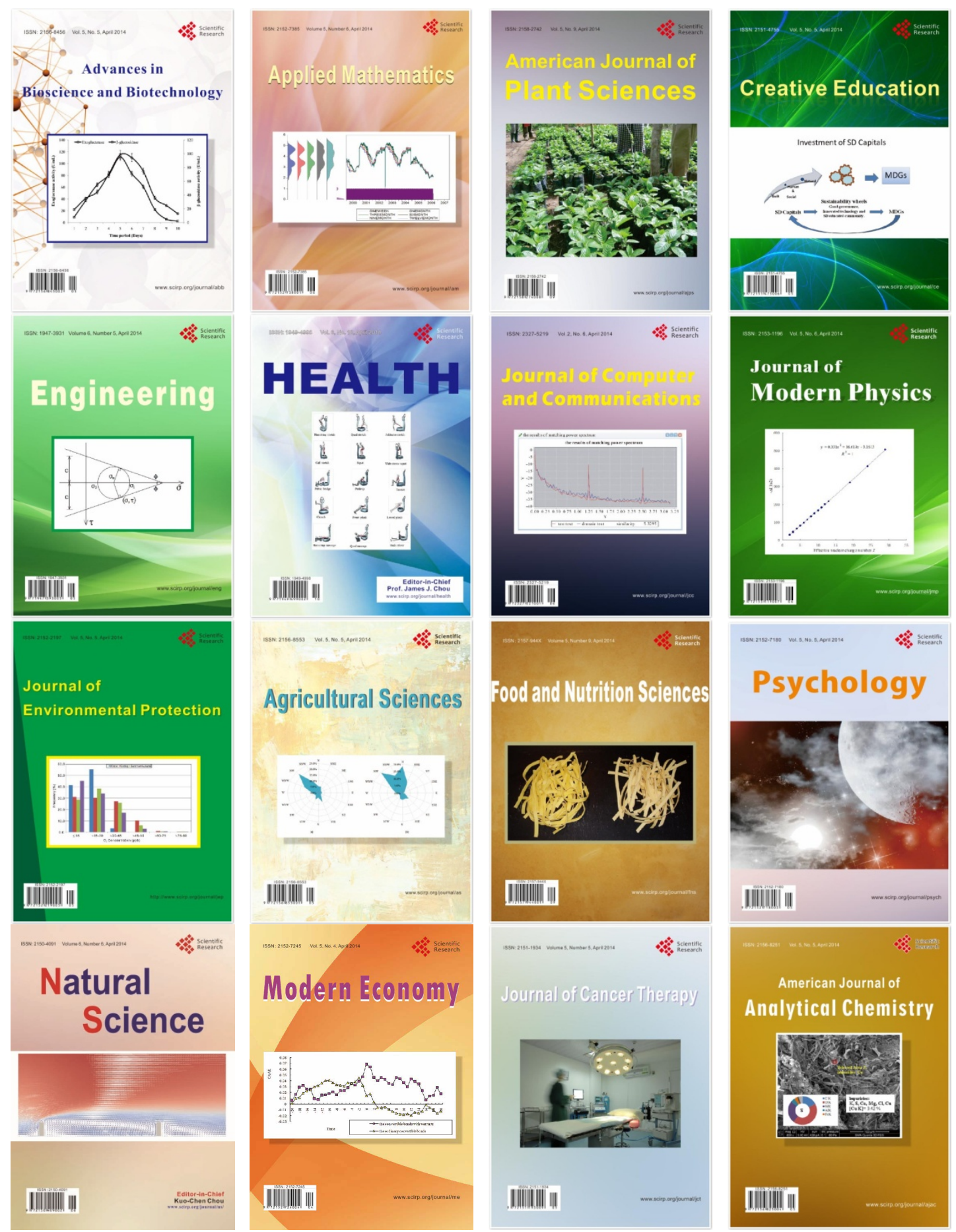